\title{
ALTINTAŞ (KÜTAHYA-TÜRKİYE) OVASI TARIM TOPRAKLARINDA AĞIR METAL KİRLILIĞININ ARAŞTIRILMASI, ÖNCEL ÇALIŞMA
}

\author{
Preliminary Investigation of Heavy Metal Pollution in Agricultural Soils of Altıntaş (Kütahya- \\ Turkey)
}

\author{
Cafer ÖZKUL ${ }^{1}$, Recep Uğur ACAR ${ }^{1}$, Necla KÖPRÜBAȘI ${ }^{2}$, Ali Emre ER ${ }^{1}$, Halil İbrahim ${ }^{1}$ \\ KIZILKAYA $^{1}$, Muharrem METIN ${ }^{1}$ ve Musa Namık SENEL $^{1}$
}

\section{ÖZET}

Altıntaş ovası, Ege Bölgesi'nin iç kısmında Kütahya ilinin yaklaşık 40 km güneyinde yer alan, tarımsal faaliyetlerin yoğun olarak yapıldığı bir bölgedir. Bir öncel çalışma niteliğinde olan bu çalışma da; Altıntaş ovasındaki tarım topraklarının ağır metal kirliliğini değerlendirmek için farklı ürünlerin yetiştiği tarım arazileri üzerinden 15 noktadan örnekleme $(0-15 \mathrm{~cm})$ yapılmıştır. Toprak örneklerindeki ağır metal içerikleri ICP-MS ile analiz edilmiştir. Çalışma alanından alınan toprak örneklerinin ağır metal içerikleri sırası ile As için 12.90-70.20 mg/kg; Cr için 29.30-137.70 $\mathrm{mg} / \mathrm{kg}$; Cu için 14.44-32.87 mg/kg; Hg için 0.02-0.56 mg/kg; Ni için 70.10-254.20 mg/kg; Pb için 10.01-29.16 mg/kg; Sb için 0.33-1.66 mg/kg ve Zn için 30.50-75.80 mg/kg arasında değişmektedir. Ayrıca Zenginleşme Faktörü (EF), Jeobirikim İndeksi ( $\mathrm{I}_{\text {geo }}$ ), Kirlilik Faktörü (CF) ve Kirlilik Yük İndeksi (PLI) topraklardaki ağır metal kirliliğini değerlendirmek için hesaplanmıştır.

\section{ABSTRACT}

Altıntaş plain is part of the Aegean Region, about $40 \mathrm{~km}$ south of Kütahya province, where agricultural activities are intense. In this preliminary study, in order to evaluate the heavy metal pollution of agricultural soils in Altıntaş plain, 15 samples $(0-15 \mathrm{~cm})$ were taken from the farms where different crops grown. Heavy metal contents in soil samples were analyzed by ICP-MS. The heavy metal contents of soil samples taken from the study area are 12.90 to 70.20 $\mathrm{mg} / \mathrm{kg}$ for As; 29.30 to $137.70 \mathrm{mg} / \mathrm{kg}$ for Cr; 14.44 to $32.87 \mathrm{mg} / \mathrm{kg}$ for $\mathrm{Cu} ; 0.02$ to $0.56 \mathrm{mg} / \mathrm{kg}$ for $\mathrm{Hg} ; 70.10$ to 254.20 $\mathrm{mg} / \mathrm{kg}$ for $\mathrm{Ni} ; 10.01$ to $29.16 \mathrm{mg} / \mathrm{kg}$ for $\mathrm{Pb} ; 0.33$ to $1.66 \mathrm{mg} / \mathrm{kg}$ for Sb and 30.50 to $75.80 \mathrm{mg} / \mathrm{kg}$ for $\mathrm{Zn}$, respectively. Enrichment Factor (EF), Geoaccumulation Index ( $\left.\mathrm{I}_{\text {geo }}\right)$, Contamination Factor (CF) and Pollution Load Index (PLI) were also utilized to assess the heavy metal contamination in soils.

\section{GİRIŞ}

Tarım alanlarındaki toprak ağır metal kirliliği, özellikle gıda güvenliği ve ekosistem üzerindeki zararlı etkileri nedeniyle son yıllarda oldukça önem arz etmektedir. Tarım topraklarındaki ağır metallerin kaynağı jeojenik ve/veya antropojenik kaynaklı olabilmektedir. Jeojenik kirlilik tamamıyla toprağ oluşturan ana malzemenin bileşiminden kaynaklanmaktadır. Gübre ve pestisidlerin aşırı kullanımı, fosil yakıtların kullanımı, madencilik faaliyetleri, hızlı nüfus artışı ve buna bağlı artan kentleşme, kontrolsüz atık su deşarjı, atmosferik birikim, trafik yoğunluğu ve artan endüstriyel faaliyetler ise tarım topraklarındaki antropojenik kirliliğin ana kaynaklarını oluşturmaktadır (Nicholson ve diğ., 2003; Romic ve Romic, 2003; Gil ve diğ., 2004; Zhang, 2006; Chary ve diğ., 2008; Zhao ve diğ., 2008; Cai ve diğ., 2009; Li ve diğ., 2009).

\footnotetext{
${ }^{1}$ Dumlupınar Üniversitesi, Mühendislik Fakültesi, Jeoloji Müh. Bl. Merkez Kampüs Merkez-KÜTAHYA e-mail:cafer.ozkul@dpu.edu.tr, recep.uguracar@dpu.edu.tr

${ }^{2}$ Kocaeli Üniversitesi, Mühendislik Fakültesi, Jeoloji Müh. Bl. Umuttepe Yerleşkesi İZMíT-KOCAELİ.

e-mail: neclakop@kocaeli.edu.tr

*ilgili yazar / Corresponding author: cafer.ozkul@dpu.edu.tr

Gönderim Tarihi: 23.05.2018

Kabul Tarihi: 05.06.2018
} 
Tarım topraklarının ağır metaller tarafından kirletilmesi, sadece tarım arazilerinin eko-çevrelerini tehlikeye sokmakla kalmadığ 1 gibi, aynı zamanda besin zinciri yoluyla bu alanlardan faydalanan insanlar dâhil tüm canlılar için ciddi tehlikeler oluşturmaktadır (Chen, 1996; Zheng ve diğ., 2002; 2003). Bu durum özellikle artan insan nüfusu ve buna bağlı besin ihtiyacının karşılanması karşısında gün geçtikçe büyüyen bir problem haline dönüşmektedir.

Ağır metaller, genellikle yoğunluğu $5 \mathrm{~g} / \mathrm{cm} 3$ ten daha yüksek olan ve ayrıca kirletici ve/veya toksik özellik taşıyan metaller ya da yarı-metaller (metalloidler) olarak tanımlanmaktadır (Duffus, 2002; Kahvecioğlu ve diğ., 2009). Ağır metallerin insan organizmasına solunum, sindirim sistemi ve cilt yoluyla girdiği gözlenmektedir (Ljung, 2006; Nieć ve diğ., 2013). Organizmaya kolay bir şekilde girmelerine rağmen bu metallerin metabolizmadan dışarı atılmaları o kadar da kolay olmamaktadır ve zamanla organizmada birikim göstermektedirler. Bu birikimlerin zamanla insanlarda oluşturduğu sağlı problemlerinin çoğu ileri derecede tanı ve tedavi olanakları gerektiren kronik hastalıklar ya da kanserlerdir (Özbolat ve Tuli, 2016).

İnsan sağlı̆̆ı için son derece önemli olan ülkemiz tarım alanları topraklarının ağır metal içerikleri ile ilgili çalışmalar yeterli sayıda değildir. Kütahya ilinin önemli tarım alanlarından birisi olan Altıntaş ovası topraklarında ise bu içerikte bir çalışma daha önce yapılmamıştır. Bir ön araştırma niteliğinde olan bu çalışmanın amacı Altıntaş ovasında seçilen pilot bölgede tarım topraklarının ağır metal kirlilik düzeylerini belirlemektir. Bu kapsamda, seçilen bölgede 15 örnekleme noktasında yer alan toprakların ağır metal içerikleri (As, $\mathrm{Cr}, \mathrm{Cu}, \mathrm{Hg}, \mathrm{Ni}, \mathrm{Pb}, \mathrm{Sb}$ ve $\mathrm{Zn}$ ) belirlenmiştir. Ayrıca bu topraklar için, Zenginleşme Faktörü, Jeobirikim İndeksi, Kirlilik Faktörü ve Kirlilik Yük İndeksi parametreleri kullanılarak ağır metal kirlilik düzeyleri açısından değerlendirme yapılmıştır.

\section{Çalışma Alanı}

Altıntaş ovası, Ege Bölgesi’nin İç Batı Anadolu Bölümü’nde yer almakta olup Kütahya ilinin yaklaşık 40 km güneyindedir (Şekil 1). Çalışma alanı, İç Anadolu Bölgesi ile Ege Bölgesi arasında yaklaşık 20 $\mathrm{km}^{2}$ alana sahip bir geçiş bölgesinde, $39^{\circ} 03^{\prime} 59^{\prime \prime}$ ile $39^{\circ} 07^{\prime} 28^{\prime \prime}$ Kuzey enlemleri ve $30^{\circ} 06^{\prime} 19^{\prime \prime}$ ile $30^{\circ}$ 12' 04" Doğu boylamları arasında ve ortalama 1015 m rakıma sahip bir alanda konumlanmaktadır. Genellikle peneplen özellik gösteren ve yoğun tarım alanlarından oluşan Altıntaş Ovası üzerinde yöre ekonomisinde önemi olan ayçiçeği ve şeker pancarı gibi sanayi bitkileri, sebze, tahıl ve hayvan yemleri üretimi yapılmaktadır. 


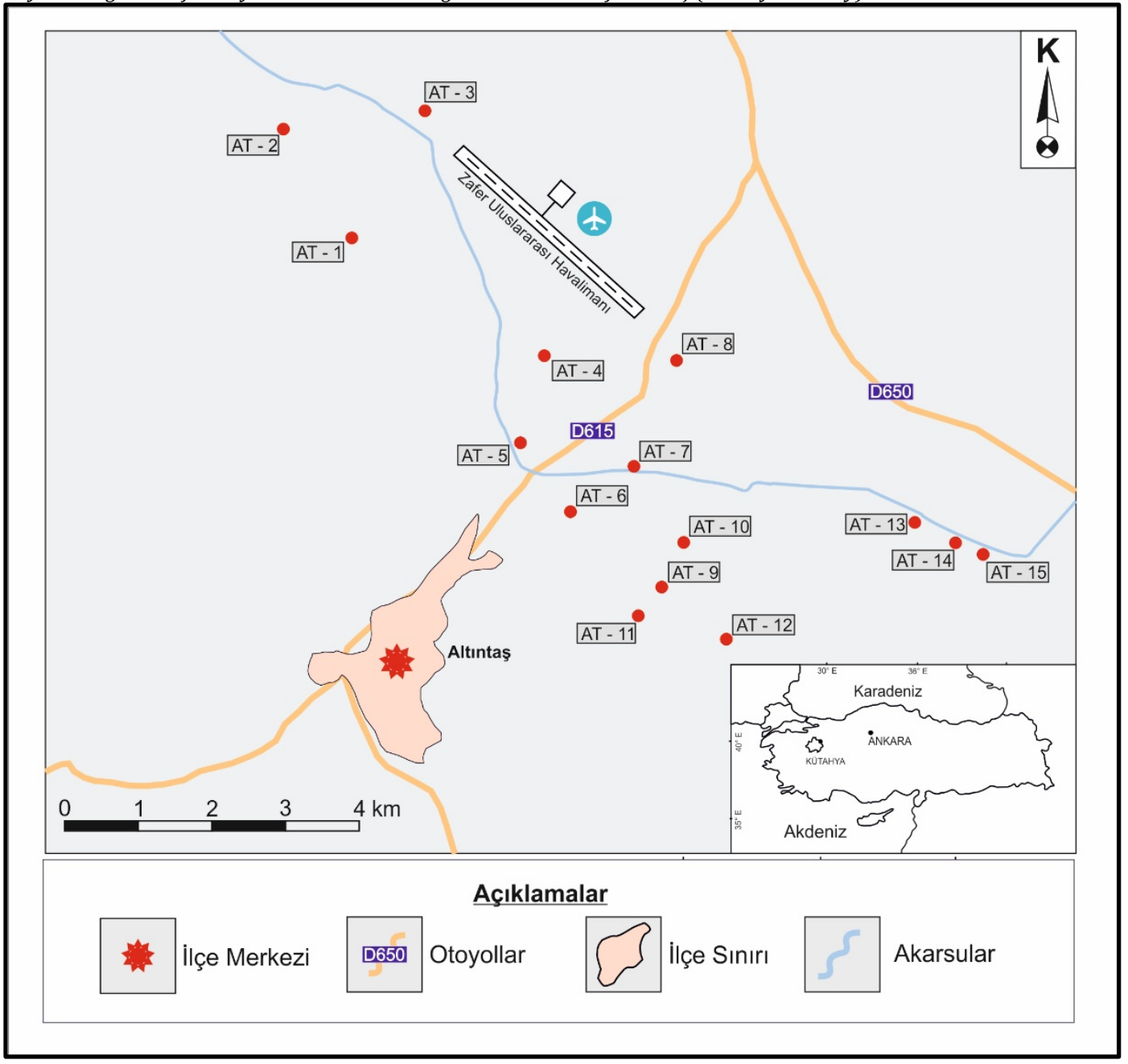

Şekil 1. Çalışma alanına ait yer bulduru ve örnekleme haritası

Figure 1. Location and sampling map of the study area

\section{Topografya ve iklim}

Çalışma alanı, Orta Anadolu havzası ile Batı Ege platosu arasında iç Batı Anadolu eşiği üzerinde bulunmaktadır. Gerek dağ ve tepe dizileri, gerek çukur sahalar, eşiğin genel karakterine uygun olarak kuzeybat1 - güneydoğu istikametinde uzanırlar. Yellice Dağı (1764 m), Gümüş Dağ1 (1901 m), Yeşil Dağ (1533 m), Türkmen Dağ (1829 m), Murat Dağ 1 (2312 m), Şaphane Dağ 1 (2121 m) ve Eğrigöz Dağı (2312 m) ile Kütahya, Köprüören, Tavşanlı, Altıntaş, Aslanapa, Gediz, Simav ve Örencik ovaları bölgenin topografyasını oluştururlar (KIÇDR, 2017).

Ege ile İç Anadolu Bölgesi arasında kalan çalışma alanı bir geçiş noktasında yer almaktadır. İklim bakımından, her iki bölgenin de özelliklerini taşımaktadır. İç Anadolu'nun soğuk iklimi ile Ege'nin 1lık iklimi arasında bir geçiş özelliği gösterir. Buna göre, yazlar sıcak ve kurak, kışlar ise soğuk ve yağışlı geçer. Yıllık sıcaklık ortalaması $10.5^{\circ} \mathrm{C}$ 'dir. En sıcak aylar, temmuz ve ağustos, en soğuk aylar ise ocak ve şubattır. Bölgede ölçülen en yüksek sıcaklık, $38,6^{\circ} \mathrm{C}^{\prime}$ dir. En düşük ölçülen sıcaklık ise 28,1 ${ }^{\circ} \mathrm{C}$ 'dir. Yağışlar, karasal iklime bağlı olarak, kış, ilkbahar ve sonbaharda görülür. Yazları genellikle kuraktır. Yıllık ortalama yağış miktarı 565 mm'dir. En yağışlı ay aralık, en kurak ay ağustostur. Yağışların \%38,8 i kış, \%29,4 'ü ilkbahar, \%12,5 'i yaz, \%19,3 'ü sonbahar aylarında düşer. Kış aylarında yağışlar, genellikle kar şeklinde, diğer mevsimlerde yağmur şeklinde görülür. Bölgedeki hâkim rüzgâr yönü ise kuzey-kuzeybatıdır (KİÇDR, 2017). 


\section{Jeolojik Özellikler}

Çalışma sahasında; Paleozoyik, Mesozoyik ve Senozoyik yaşlı litolojik birimler yüzeylenmektedir (Şekil 2). Stratigrafik olarak en alt konumda bulunan Paleozoyik yaşlı ayrılmamış gnayslardan oluşan kayaçlar sahada temel kayaçları oluşturmaktadır. Bu temel kayaçların üzerine stratigrafik olarak altta şist-kalkşist ve onun üzerinde mermerden oluşan Triyas- Jura yaşlı bir metamorfik birim gelmektedir. Neojen yaşlı gölsel ortam kökenli kireçtaşı, marn ve şeyllerden oluşan birim çalışma alanında geniş alanlarda yüzeylenmekte olup yer yer Kuvaterner yaşl1 kum, çakıl ve siltten oluşan alüvyal çökeller bu birimi örtmektedir (M.T.A., 2002).

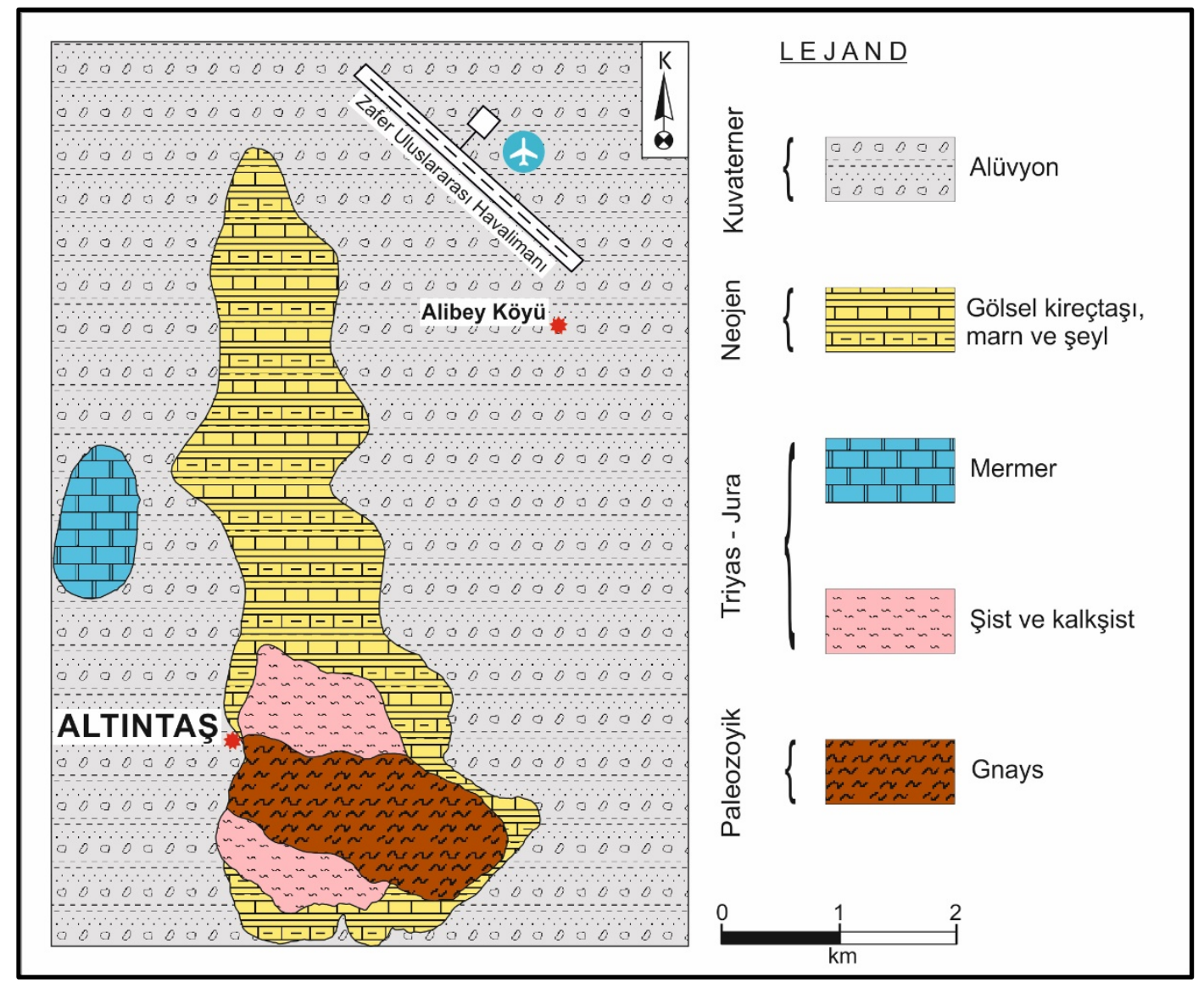

Şekil 2. Çalışma alanına ve civarına ait genel jeoloji haritası (M.T.A., 2002'den değiştirilerek alınmıştır)

Figure 2. General geological map of the study area and surroundings (Modified from M.T.A., 2002)

\section{MATERYAL ve METOT}

Çalışma materyalini, Kütahya ili Altıntaş ilçesinde yer alan Altıntaş ovasının tarım alanlarından alınan toplam 15 toprak örneği oluşturmaktadır. Çalışma bir ön araştırma niteliğinde olduğu için çalışma alanı ve örnek sayısı sinırlı tutulmuştur. Toprak örnekleri yüzeyden $15 \mathrm{~cm}$ derinliğe kadar olan kısımdan toplanmıştır. Örnekleme, Nisan 2017 ayı içerisinde gerçekleştirilmiştir. Örnekleme noktaları Zafer Havalimanı, Kütahya-Afyon Karayolu ve Altıntaş ilçe merkezi arasında kalan tarım alanlarından rastgele olarak seçilmiştir. Çalışma alanında seçilen örnekleme noktaları Şekil 1'de gösterilmektedir. Örnekleme işlemi için plastik kürek kullanılmıştır ve her örnekleme noktasından yaklaşık bir kilogram toprak örneği alınmıştır. Örnekler analiz işlemine kadar polietilen torbalar içinde saklanmıştır. 
Altıntaş (Kütahya-Türkiye) Ovası Tarım Topraklarında Ağır Metal Kirliliğinin Araştırılması, Öncel Çalışma Preliminary Investigation of Heavy Metal Pollution İn Agricultural Soils of Altıntaş (Kütahya-Turkey)

Tarım alanlarından alınan toprak örnekleri laboratuvar ortamında oda sıcaklığında 5 gün süre ile kurutulmuştur. Örneklerin içerisindeki topaklanmalar tahta havan yardımıyla ezilmiştir. Daha sonra toprak örnekleri kimyasal analizler için ideal olan $177 \mu$ m'lik tane boyu elde etmek için 80 numaralı elekten geçirilmiştir (Rose ve diğ., 1991; Thomson, 1986).

Örneklerin çözündürme işlemi, $0.5 \mathrm{~g}$ kuru toz halindeki toprak örneğinin Aqua Regia (AR) solüsyonunda $\left(\mathrm{HCl}+\mathrm{HNO}_{3}+\mathrm{H}_{2} \mathrm{O}\right) 95{ }^{0} \mathrm{C}$ 'de teflon basınçlı krozölerde 1 saat süreyle yapılmıştır. $\mathrm{Bu}$ yöntem, toplama en yakın çözündürme yöntemlerinden birisi olduğu için toprak analizlerinde sıklıkla kullanılmaktadır (Chen ve Ma, 2001). Elde edilen çözeltilerden $\mathrm{As}, \mathrm{Cr}, \mathrm{Cu}, \mathrm{Hg}, \mathrm{Ni}, \mathrm{Pb}, \mathrm{Sb}$ ve $\mathrm{Zn}$ ağır metallerinin konsantrasyon ölçümleri ICP-MS yöntemi ile ACME (Kanada) laboratuvarlarında yaptırılmıştır.

Topraklardaki ağır metal zenginleşme ve kirlilik seviyelerinin tespit edilmesi amacıyla; Zenginleşme Faktörü (Enrichment Factor, EF), Jeobirikim İndeksi (Geoaccumulation Index, Igeo), Kirlilik Faktörü (Contamination Factor, CF) ve Kirlilik Yük İndeksi (Pollution Load Index, PLI) parametreleri sıklıkla kullanılmaktadır. $\mathrm{Bu}$ çalışmada da bu parametrelerden çalışma alanındaki ağır metal kirlilik seviyelerinin belirlenmesi için yararlanılmıştır.

\section{Zenginleşme Faktörü (Enrichment Factor, EF)}

Zenginleşme faktörü (EF), topraktaki ağır metal kirlilik oranını belirlemek ve kıyaslamak için sıklıkla kullanılan önemli bir göstergedir (Buat-Menard ve Chesselet, 1979). EF değeri, ölçülen bir element miktarının, aynı elemente ait referans değerine göre normalize edilmesiyle hesaplanır. Referans element, topraktaki konsantrasyonunun değişmemesi ve çok düşük kimyasal reaksiyona sahip olması ile karakterize olur (Barbieri, 2016). En sik kullanılan referans elementler Al, Fe, Mn, Sc, Ti ve Zr elementleridir (Quevauviller ve diğ,. 1989; Pacyna ve Winchester, 1990; Schiff ve Weisberg, 1999; Reimann ve de Caritat, 2000; Sutherland, 2000; Chatterjee ve di ̆̆., 2007, Machender ve diğ., 2011; Vural, 2014). Bu çalışmada, referans element olarak $\mathrm{Mn}$ elementi seçilmiştir. Çalışılan tüm elementlerin referans değerlerinde ise Brooks (1972) tarafindan belirlenen toprak değerlerinden yararlanılmıştır. Zenginleşme Faktörü (EF) aşağıdaki formülle hesaplanabilir:

$E F=\left(C_{n} / C_{\text {ref }}\right)_{\text {örnek }} /\left(B_{n} / B_{\text {ref }}\right)_{\text {referans }}$

Formülde, $C_{n}$ : Analizi yapılan örnekteki elementin değeri; $C_{r e f}$ : Analizi yapılan örnekteki referans elementin değeri; $B_{n}$ : Brooks (1972)'a göre elementin topraktaki ortalama değeri; $B_{\text {ref: }}$ Brooks (1972)'a göre referans elementin topraktaki ortalama değeri olarak kullanılmıştır. Zenginleşme Faktörü Sutherland (2000) tarafindan sınıflanmıştır;

\begin{tabular}{ll}
\hline $\mathrm{EF}<2$ & Minimal zenginleşme \\
$2 \leq \mathrm{EF} \leq 5$ & Orta zenginleşme \\
$5 \leq \mathrm{EF} \leq 20$ & Belirgin zenginleşme \\
$20 \leq \mathrm{EF} \leq 40$ & Çok yüksek zenginleşme \\
$\mathrm{EF}>40$ & Aş̧rı zenginleşme \\
\hline
\end{tabular}

\section{Jeobirikim İndeksi (Geoaccumulation Index, $\mathbf{I}_{\text {geo }}$ )}

Jeobirikim indeksi ( $\mathrm{I}_{\text {geo }}$ ), günümüzdeki mevcut element değerlerini endüstrileşme öncesi değerlerle karşılaştırarak toprakta meydana gelen metal kirliliğin seviyesini belirlemek için kullanılmaktadır. İndeks Müller (1969) tarafından önerilmiştir ve toprak kirliliğinin değerlendirilmesi için pek çok 
Uygulamalı Yerbilimleri Dergisi, Cilt: 17, No: 1, 2018 (13-26)

Journal of Applied Earthsciences, Vol: 17, No: 1, 2018 (13-26)

Cafer ÖZKUL, vd.

araştırmacı tarafından yaygın olarak kullanılmaktadır (Miko ve diğ., 2000; Loska ve diğ., 2003; Sengupta ve diğ. 2010; Chung ve Chon, 2014; Vural, 2014). Jeobirikim indeksi aşağıdaki eşitlik ile hesaplanabilir.

$I_{\text {geo }}=\log _{2}\left(C_{n} /\left(1.5 \times B_{n}\right)\right)$

Eşitlikte, $C_{n}$ : Toprak örneğindeki metal konsantrasyonunun değeri; $B_{n}$ : n metalin topraktaki ortalama değeri (Brooks, 1972); 1.5: Temel değer matriksi korelasyon faktörü (çok küçük antropojenik etkilerden dolayı) değerlerine karşılık gelmektedir. Jeobirikim indeksi Müller (1969; 1981) tarafından 7 ayrı kirlilik sınıfına ayrılmıştır;

\begin{tabular}{lll}
\hline Sınıfi & Değer & Kirlilik Derecesi \\
\hline 0 & $\mathrm{I}_{\text {geo }}<0$ & Pratik olarak kirlenmemiş \\
1 & $0<\mathrm{I}_{\text {geo }}<1$ & Kirlenmemiş-orta derecede kirlenmiş \\
2 & $1<\mathrm{I}_{\text {geo }}<2$ & Orta derecede kirlenmiş \\
3 & $2<\mathrm{I}_{\text {geo }}<3$ & Orta-çok kirlenmiş \\
4 & $3<\mathrm{I}_{\text {geo }}<4$ & Çok kirlenmiş \\
5 & $4<\mathrm{I}_{\text {geo }}<5$ & Çok-aşırı kirlenmiş \\
6 & $\mathrm{I}_{\text {geo }}>5$ & Aşırı kirlenmiş \\
\hline
\end{tabular}

Kirlilik Faktörü (Contamination Factor, CF) ve Kirlilik Yük İndeksi (Pollution Load Index, PLI)

Kirlilik faktörü (CF), Hakanson (1980) tarafından önerilmiştir. Topraktaki kirlilik derecesinin belirlenmesinde kullanılır. CF, çalışılan topraktaki ağır metal değerinin toprak ortalama değerine (Brooks, 1972) bölünmesiyle elde edilir ve aşağıdaki formülle hesaplanabilir:

$C F=C_{\text {metal }} / C_{0}$

Formülde, $C_{\text {metal }}$ : Toprak örneğindeki metal konsatrasyonu; $C_{0}$ : Brooks (1972)’a göre metalin topraktaki ortalama değeri olarak kullanılmaktadır. Kirlilik Faktörü Hakanson (1980) tarafından sınıflandırılmıştır;

\begin{tabular}{ll}
\hline CF Değeri & Kirlilik Derecesi \\
\hline $\mathrm{CF}<1$ & Az kirlenme \\
$1<\mathrm{CF}<3$ & Orta derecede kirlenme \\
$3<\mathrm{CF}<6$ & Önemli derecede kirlenme \\
$\mathrm{CF}>6$ & Aşırı derecede kirlenme \\
\hline
\end{tabular}

Kirlilik Yük İndeksi (PLI) ise, Tomlinson ve diğ. (1980) tarafından her bir örnekleme noktasındaki ağır metal kirlilik seviyesinin tespit edilmesi için önerilmiş bir indekstir. İndeks, her bir metale ait kirlilik faktörlerinin (CF) hesaplanmasıyla aşağıdaki eşitlik kullanılarak elde edilmektedir.

$\left.P L I=\sqrt[n]{(} C F_{1} \times C F_{2} \times \cdots \cdots \cdots \times C F_{n}\right)$

Eşitlikte, CF: Kirlilik faktörü; $n$ : Metal sayısına karşılık gelmektedir. Chakravarty ve Patgiri (2009)’a göre, elde edilen PLI değeri $>1$ ise o örnekleme noktasında kirlilik var, PLI değeri $<1$ ise kirlilik yok demektir. 
Altıntaş (Kütahya-Türkiye) Ovası Tarım Topraklarında Ağır Metal Kirliliğinin Araştırılması, Öncel Çalışma Preliminary Investigation of Heavy Metal Pollution İn Agricultural Soils of Altıntaş (Kütahya-Turkey)

\section{TARTIŞMA ve SONUÇLAR}

Altıntaş ovası tarım alanlarından alınan 15 toprak örneğine ait analiz sonuçları ve tanımlayıcı istatistik parametreleri Çizelge 1'de verilmiştir. Buna göre; As değerleri 12.90-70.20 mg/kg (ortalama 37.91 $\mathrm{mg} / \mathrm{kg}$ ), Cr değerleri 29.30-137.70 mg/kg (ortalama $63.69 \mathrm{mg} / \mathrm{kg}$ ), Cu değerleri 14.44-32.87 mg/kg (ortalama $22.51 \mathrm{mg} / \mathrm{kg}$ ), $\mathrm{Hg}$ değerleri $0.02-0.56 \mathrm{mg} / \mathrm{kg}$ (ortalama $0.12 \mathrm{mg} / \mathrm{kg}$ ), Ni değerleri 70.10$254.20 \mathrm{mg} / \mathrm{kg}$ (ortalama $117.19 \mathrm{mg} / \mathrm{kg}$ ), Pb değerleri 10.01-29.16 mg/kg (ortalama $20.80 \mathrm{mg} / \mathrm{kg}$ ), Sb değerleri $0.33-1.66 \mathrm{mg} / \mathrm{kg}$ (ortalama $0.64 \mathrm{mg} / \mathrm{kg}$ ) ve Zn değerleri 30.50-75.80 mg/kg (ortalama 54.58 $\mathrm{mg} / \mathrm{kg}$ ) arasında değişmektedir (Çizelge 1). Ayrıca çalışma alanındaki örnekleme noktalarına ait ağır metal konsantrasyon haritaları Şekil 3'de sunulmuştur. Konsantrasyon haritalarının hazırlanmasında ArcGIS 10 programı kullanılmıştır.

Çizelge 1. Toprak örneklerinin ağır metal içerikleri $(\mathrm{mg} / \mathrm{kg})$ ve tanımlayıcı istatistikleri Table 1. Heavy metal contents $(\mathrm{mg} / \mathrm{kg}$ ) and descriptive statistics of soil samples

\begin{tabular}{lcccccccc}
\hline Örnekleme & As & $\mathbf{C r}$ & $\mathbf{C u}$ & $\mathbf{H g}$ & $\mathbf{N i}$ & $\mathbf{P b}$ & $\mathbf{S b}$ & $\mathbf{Z n}$ \\
\hline AT-1 & 70.20 & 130.60 & 20.02 & 0.56 & 254.20 & 23.56 & 1.66 & 54.70 \\
AT-2 & 49.80 & 137.70 & 21.58 & 0.26 & 251.70 & 21.02 & 1.22 & 50.20 \\
AT-3 & 12.90 & 48.90 & 14.44 & 0.02 & 80.20 & 16.57 & 0.33 & 37.70 \\
AT-4 & 20.10 & 55.90 & 21.48 & 0.02 & 88.60 & 24.69 & 0.57 & 55.10 \\
AT-5 & 48.50 & 54.60 & 23.94 & 0.05 & 121.20 & 18.58 & 0.96 & 53.50 \\
AT-6 & 66.90 & 29.30 & 14.59 & 0.04 & 75.60 & 10.01 & 0.62 & 30.50 \\
AT-7 & 44.50 & 55.50 & 23.23 & 0.05 & 120.50 & 20.99 & 0.71 & 50.00 \\
AT-8 & 24.10 & 54.90 & 26.19 & 0.03 & 95.10 & 24.91 & 0.45 & 62.10 \\
AT-9 & 46.40 & 60.80 & 25.56 & 0.04 & 105.60 & 20.93 & 0.53 & 58.20 \\
AT-10 & 61.10 & 70.40 & 26.39 & 0.02 & 123.50 & 22.02 & 0.58 & 62.70 \\
AT-11 & 17.80 & 45.80 & 16.90 & 0.03 & 84.10 & 14.99 & 0.37 & 46.30 \\
AT-12 & 32.80 & 53.80 & 21.84 & 0.54 & 106.30 & 19.71 & 0.50 & 54.10 \\
AT-13 & 29.30 & 60.40 & 25.99 & 0.04 & 104.20 & 24.03 & 0.39 & 75.80 \\
AT-14 & 14.60 & 47.90 & 22.64 & 0.03 & 76.90 & 20.80 & 0.41 & 59.20 \\
AT-15 & 29.70 & 48.80 & 32.87 & 0.03 & 70.10 & 29.16 & 0.33 & 68.60 \\
& & & & & & & & \\
Ortalama & 37.91 & 63.69 & 22.51 & 0.12 & 117.19 & 20.80 & 0.64 & 54.58 \\
Ortanca & 32.80 & 54.90 & 22.64 & 0.04 & 104.20 & 20.99 & 0.53 & 54.70 \\
Minimum & 12.90 & 29.30 & 14.44 & 0.02 & 70.10 & 10.01 & 0.33 & 30.50 \\
Maksimum & 70.20 & 137.70 & 32.87 & 0.56 & 254.20 & 29.16 & 1.66 & 75.80 \\
Basıklık & -1.12 & 3.25 & 0.51 & 2.91 & 3.09 & 1.30 & 3.26 & 0.81 \\
Çarpıklık & 0.34 & 1.97 & 0.06 & 2.05 & 1.98 & -0.65 & 1.85 & -0.35 \\
Standart Sapma & 18.97 & 30.00 & 4.84 & 0.19 & 57.75 & 4.60 & 0.37 & 11.27 \\
\hline & & & & & & & &
\end{tabular}




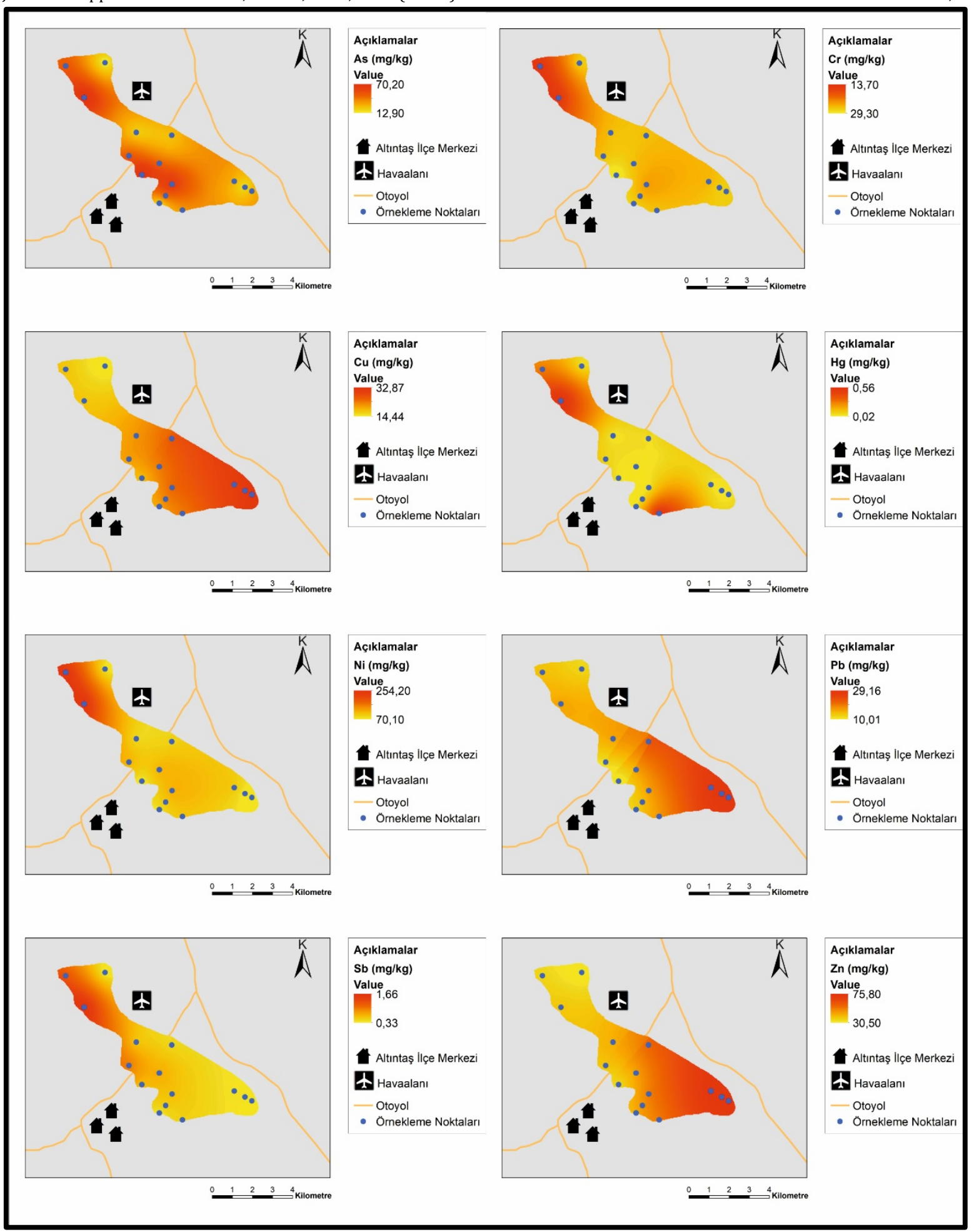

Şekil 3. Çalışma alanına ait ağır metal konsantrasyon haritaları

Figure 3. Heavy metals concentration maps of the study area

Altıntaş ovası çalışma alanındaki topraklarda 8 ağır metal için hesaplanan;

Zenginleşme Faktörüne (EF) göre; As 3.64-20.81 (orta zenginleşme - çok yüksek zenginleşme), $\mathrm{Cr}$ 0.16-0.95 (minimal zenginleşme), $\mathrm{Cu}$ 0.81-2.87 (minimal zenginleşme - orta zenginleşme), $\mathrm{Hg}$ 2.2277.59 (orta zenginleşme - aşırı zenginleşme), Ni 2.09-8.88 (minimal zenginleşme - belirgin 
Altıntaş (Kütahya-Türkiye) Ovası Tarım Topraklarında Ağır Metal Kirliliğinin Araştırılması, Öncel Çalışma Preliminary Investigation of Heavy Metal Pollution İ Agricultural Soils of Altıntaş (Kütahya-Turkey)

zenginleşme), $\mathrm{Pb}$ 1.11-4.69 (minimal zenginleşme - orta zenginleşme), Sb 0.80-4.64 (minimal zenginleşme - orta zenginleşme) ve $\mathrm{Zn} \mathrm{0.67-2.61} \mathrm{(minimal} \mathrm{zenginleşme} \mathrm{-} \mathrm{orta} \mathrm{zenginleşme)} \mathrm{arasında}$ zenginleşme göstermektedir. Özellikle cıvadaki aşırı, arsenikteki çok yüksek ve nikeldeki belirgin dereceye varan zenginleşme değerleri dışında diğer ağır metaller için Altıntaş tarım topraklarında önemli bir zenginleşme tespit edilmemiştir (Çizelge 2).

Çizelge 2. Zenginleşme faktörüne göre toprak örneklerinde gözlenen ağır metal zenginleşmeleri Table 2. Heavy metal enrichments in the soil samples according to enrichment factor

\begin{tabular}{lcccccccc}
\hline Örnekleme & EF-As & EF-Cr & EF-Cu & EF-Hg & EF-Ni & EF-Pb & EF-Sb & EF-Zn \\
\hline Ortalama & 10.77 & 0.46 & 1.63 & 15.70 & 4.20 & 2.99 & 1.83 & 1.58 \\
Minimum & 3.64 & 0.16 & 0.81 & 2.22 & 2.09 & 1.11 & 0.80 & 0.67 \\
Maksimum & 20.81 & 0.95 & 2.87 & 77.59 & 8.88 & 4.69 & 4.64 & 2.61 \\
\hline \multicolumn{7}{c}{ Örnek Sayısı } \\
\hline $\mathbf{E F}<\mathbf{2}$ & - & 15 & 13 & - & - & 1 & 11 & 13 \\
$\mathbf{2} \leq \mathbf{E F} \leq \mathbf{5}$ & 2 & - & 2 & 8 & 13 & 14 & 4 & 2 \\
$\mathbf{5} \leq \mathbf{E F} \leq \mathbf{2 0}$ & 12 & - & - & 4 & 3 & - & - & - \\
$\mathbf{2 0} \leq \mathbf{E F} \leq \mathbf{4 0}$ & 1 & - & - & 1 & - & - & - & - \\
$\mathbf{E F}>\mathbf{4 0}$ & - & - & - & 2 & - & - & - & - \\
\hline
\end{tabular}

Jeobirikim İndeksine ( $\mathrm{I}_{\mathrm{geo}}$ ) göre; As 0.78-3.23 (kirlenmemiş-orta derecede kirlenmiş - çok kirlenmiş), $\mathrm{Cr}$ (-3.36)-(-1.12) (pratik olarak kirlenmemiş), $\mathrm{Cu}$ (-1.05)-0.13 (pratik olarak kirlenmemiş kirlenmemiş-orta derecede kirlenmiş), Hg 0.18-5.21 (kirlenmemiş-orta derecede kirlenmiş - aşırı kirlenmiş), Ni 0.22-2.08 (kirlenmemiş-orta derecede kirlenmiş - orta-çok kirlenmiş), $\mathrm{Pb}$ (-0.58)-0.96 (pratik olarak kirlenmemiş - kirlenmemiş-orta derecede kirlenmiş), Sb (-1.18)-1.15 (pratik olarak kirlenmemiş - orta derecede kirlenmiş) ve Zn (-1.30)-0.02 (pratik olarak kirlenmemiş - kirlenmemişorta derecede kirlenmiş) arasında değerler belirlenmiştir. Cr ağır metali açısından bölge toprakların herhangi bir kirlenme görülmezken, $\mathrm{Cu}, \mathrm{Pb}, \mathrm{Sb}$ ve $\mathrm{Zn}$ ağır metalleri için ise kirlilik orta dereceye varan düzeylerde gerçekleşmiştir. Çalışma alanındaki topraklarda en fazla kirlilik oluşturan ağır metaller ise $\mathrm{Hg}$ ve onu takip eden As ve Ni olmuştur (Çizelge 3).

Çizelge 3. Jeobirikim indeksine göre toprak örneklerinde gözlenen ağır metal zenginleşmeleri Table 3. Heavy metal pollution level of the soil samples according to geoaccumulation index

\begin{tabular}{|c|c|c|c|c|c|c|c|c|}
\hline Örnekleme & $\mathbf{I}_{\text {geo }}-$ As & $\mathbf{I}_{\text {geo }}-\mathrm{Cr}$ & $\mathbf{I}_{\text {geo }}-\mathrm{Cu}$ & $\mathbf{I}_{\text {geo }}-\mathrm{Hg}$ & $\mathbf{I}_{\text {geo }}-\mathrm{Ni}$ & $\mathbf{I}_{\text {geo }}-\mathbf{P b}$ & $\mathbf{I}_{\mathrm{geo}}-\mathrm{Sb}$ & $\mathbf{I}_{\text {geo }}-\mathbf{Z n}$ \\
\hline Ortalama & 2.15 & -2.35 & -0.45 & 1.75 & 0.85 & 0.43 & -0.40 & -0.49 \\
\hline Minimum & 0.78 & -3.36 & -1.05 & 0.18 & 0.22 & -0.58 & -1.18 & -1.30 \\
\hline Maksimum & 3.23 & -1.12 & 0.13 & 5.21 & 2.08 & 0.96 & 1.15 & 0.02 \\
\hline \multicolumn{9}{|c|}{ Örnek Sayısı } \\
\hline Igeo $<0$ & - & 15 & 14 & - & - & 1 & 12 & 14 \\
\hline $0<$ I $_{\text {geo }}<\mathbf{1}$ & 2 & - & 1 & 7 & 10 & 14 & 2 & 1 \\
\hline $1<\mathrm{I}_{\mathrm{geo}}<2$ & 5 & - & - & 5 & 3 & - & 1 & - \\
\hline $2<\mathbf{I}_{\text {geo }}<3$ & 5 & - & - & - & 2 & - & - & - \\
\hline $3<\mathrm{I}_{\mathrm{geo}}<4$ & 3 & - & - & - & - & - & - & - \\
\hline $4<\mathbf{I}_{\mathrm{geo}}<5$ & - & - & - & 1 & - & - & - & - \\
\hline $\mathbf{I}_{\mathrm{geo}}>5$ & - & - & - & 2 & - & - & - & - \\
\hline
\end{tabular}


Uygulamalı Yerbilimleri Dergisi, Cilt: 17, No: 1, 2018 (13-26)

Journal of Applied Earthsciences, Vol: 17, No: 1, 2018 (13-26)

Cafer ÖZKUL, vd.

Kirlilik Faktörüne (CF) göre; As 2.58-14.04 (orta derecede kirlenme - aşırı derecede kirlenme), $\mathrm{Cr}$ 0.15-0.69 (az kirlenme), Cu 0.72-1.64 (az kirlenme - orta derecede kirlenme), Hg 1.70-55.50 (orta derecede kirlenme - aşırı derecede kirlenme), Ni 1.75-6.36 (orta derecede kirlenme - aşırı derecede kirlenme), Pb 1.00-2.92 (orta derecede kirlenme), Sb 0.66-3.32 (az kirlenme - önemli derecede kirlenme) ve Zn 0.61-1.52 (az kirlenme - orta derecede kirlenme) arasında kirlilik tespit edilmiştir. Buna göre en fazla kirlilik gösteren ağır metaller $\mathrm{Hg}$, As ve Ni olmuştur. Diğer metaller açısından ise çok ciddi bir kirlenme söz konusu değildir (Çizelge 4).

Çizelge 4. Kirlilik faktörüne göre toprak örneklerinde gözlenen ağır metal zenginleşmeleri

Table 4. Heavy metal pollution level of the soil samples according to contamination factor

\begin{tabular}{lcccccccc}
\hline Örnekleme & CF-As & CF-Cr & CF-Cu & Cr-Hg & Cr-Ni & Cr-Pb & CF-Sb & CF-Zn \\
\hline Ortalama & 7.58 & 0.32 & 1.13 & 11.50 & 2.93 & 2.08 & 1.28 & 1.09 \\
Minimum & 2.58 & 0.15 & 0.72 & 1.70 & 1.75 & 1.00 & 0.66 & 0.61 \\
Maksimum & 14.04 & 0.69 & 1.64 & 55.50 & 6.36 & 2.92 & 3.32 & 1.52 \\
\hline \multicolumn{7}{c}{ Örnek Sayısı } \\
\hline $\mathbf{C F}<\mathbf{1}$ & - & 15 & 3 & - & - & - & 6 & 3 \\
$\mathbf{1}<\mathbf{C F}<\mathbf{3}$ & 2 & - & 12 & 6 & 10 & 15 & 8 & 12 \\
$\mathbf{3}<\mathbf{C F}<\mathbf{6}$ & 5 & - & - & 5 & 3 & - & 3 & - \\
$\mathbf{C F}>\mathbf{6}$ & 8 & - & - & 3 & 2 & - & - & - \\
\hline
\end{tabular}

Örnekleme noktaları Kirlilik Yük İndeksi (PLI) sonuçlarına göre değerlendirildiğinde ise; tüm örnekleme noktalarında PLI değerlerinin kirlilik sınır değeri olan 1 değerinin üzerinde kaldığ belirlenmiştir (Şekil 4). Buna göre her bir örnekleme noktasında araştırma konusu ağır metallerin toplamı değerlendirildiğinde örnekleme noktalarının tamamının kirlendiği tespit edilmiştir.

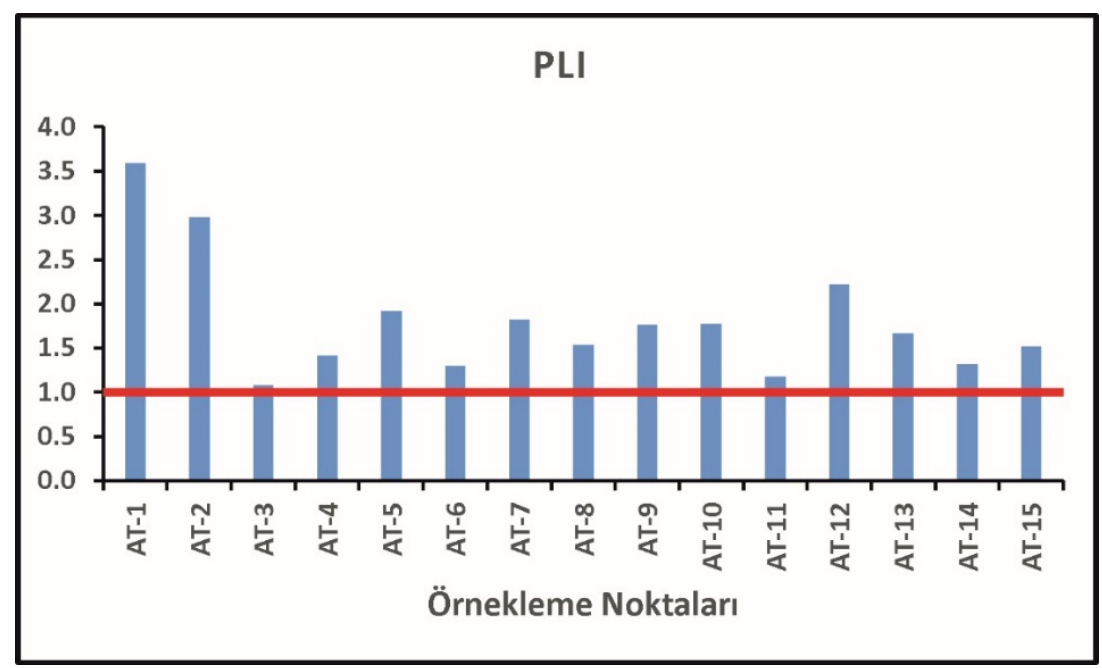

Şekil 4. Çalışma alanı örnekleme noktalarına ait Kirlilik Yük İndeksi (PLI) dağılımı

Figure 4. Pollution Load Index (PLI) distribution graphic of sample points of the study area 
Altıntaş (Kütahya-Türkiye) Ovası Tarım Topraklarında Ağır Metal Kirliliğinin Araştırılması, Öncel Çalışma Preliminary Investigation of Heavy Metal Pollution İn Agricultural Soils of Altıntaş (Kütahya-Turkey)

SONUÇLAR ve ÖNERÍLER

Altıntaş ovası tarım topraklarında ağır metal kirlilik boyutunun belirlenmesi amacıyla Zenginleşme Faktörü (EF), Jeobirikim İndeksi ( $\mathrm{I}_{\text {geo }}$ ) ve Kirlilik Faktörü (CF) parametreleri hesaplanmıştır. Bu sonuçlara göre; As, $\mathrm{Hg}$ ve Ni ağır metallerince bölge topraklarında oldukça önemli oranlarda kirlenme gözlenmektedir. $\mathrm{Cu}, \mathrm{Pb}, \mathrm{Sb}$ ve $\mathrm{Zn}$ ağır metalleri için kirlilik boyutu ciddi oranlara ulaşmamıştır. $\mathrm{Cr}$ ağır metali için ise bir kirlenme söz konusu değildir. Hesaplanan Kirlilik Yük İndeksine (PLI) göre söz konusu ağır metallerin tamamı için bir değerlendirme yapıldığında da tüm örnekleme noktalarının kirlendiği tespit edilmiştir (PLI $>1)$.

Çalışma alanındaki tarım topraklarında belirlenen bu ağır metal kirliliğinin bölgedeki trafik yoğunluğu, evsel atıklar, gübreleme ve pestisit kullanımı gibi antropojenik aktiviteler sonucunda oluştuğu düşünülmektedir. Kirlilik gösteren ağır metaller için yüksek $\mathrm{EF}, \mathrm{I}_{\text {geo }}$ ve $\mathrm{CF}$ değerleri bu görüşü destekler niteliktedir.

Sonuç olarak, Altıntaş ovası tarım toprakları ağır metallerce kirlenmiştir. Bu kirlilik boyutunu tam anlamıyla belirlemek için örnekleme yapılan bölge genişletilerek daha detaylı bir şekilde çalışılması önerilmektedir. Bu çalışma sonucuna göre bölge topraklarında insan sağlı̆̆ını tehdit etmeyecek şekilde daha kontrollü bir üretim yapılması ya da bölge topraklarının temizlenmesi veya iyileştirilmesi (remediasyon) sağlanabilir. 


\section{KAYNAKLAR}

BARBIERI, M., 2016. The Importance of Enrichment Factor (EF) and Geoaccumulation Index (Igeo) to Evaluate the Soil Contamination. J Geology \& Geophysics, 5 (1), 1 -4.

BROOKS, R. R., 1972, Geobotany and biogeochemistry in mineral exploration: New York, Harper and Row, 290 p

BUAT-MENARD, P. and CHESSELET, R., 1979. Variable influence of the atmospheric flux on the trace metal chemistry of oceanic suspended matter. Earth Planet Sci Lett, 42, 399-411.

CAI Q., LONG M.L. , ZHU M., ZHOU Q.Z., ZHANG L., LIU J., 2009. Food chain transfer of cadmium and lead to cattle in a lead-zinc smelter in Guizhou, China. Environ Pollut, 157:3078-82.

CHAKRAVARTY, I. M. and PATGIRI, A. D., 2009. Metal Pollution Assessment in Sediments of the Dikrong River, N.E. India Journal of Human Ecology, 27, 63-67.

CHARY S. C, KAMALA C. T, RAJ D. S. S., 2008. Assessing risk of heavy metals from consuming food grown on sewage irrigated soils and food chain transfer. Ecotoxicol Environ Safety, 69: 513-24.

CHATTERJEE, M., FILHO, E. V. S., SARKAR, S. K., SELlA, S. M., BHATTACHARYA, A., SATPATHYC, K. K., PRASADC, M. V. R., CHAKRABORTYA, S., BHATTACHARYAA, B. D., 2007. Distribution and possible source of trace elements in the sediment cores of a tropical macrotidal estuary and their ecotoxicological significance. Environ Int, 33, 346-356.

CHEN HUAIMAN, 1996. Heavy Metal Pollution in Soil-Plant System. Science Press, Beijing.

CHEN, M. and MA, L.Q., 2001. Comparison of three aqua regia digestion methods for twenty Florida soils. American Society of Soil Science Journal, 65, 491-499.

CHUNG, S. AND CHON, H.T., 2014. Assessment of the level of mercury contamination from some anthropogenic sources in Ulaanbaatar, Mongolia. J Geochem Explor, 147, 237-244.

DUFFUS J., 2002. Heavy metals: a meaningless term (IUPAC Technical report). Pure Appl Chem. 74, 793-807.

GIL, C., BOLUDA, R., RAMOS, J., 2004. Determination and evaluation of cadmium, lead and nickel in greenhouse soils of Almeria (Spain). Chemosphere 55 (7), 1027-1034.

HAKANSON, L., 1980. An ecological risk index for aquatic pollution control. A sedimentological approach Water Res., 14, 975-1001.

KAHVECIOĞLU, Ö., KARTAL, G., GÜVEN, A., TIMUR, S., 2009. Metallerin çevresel etkileri. Metalurji Dergisi, 136, 47-53.

KIÇDR, 2017. Kütahya il çevre durum raporu. Kütahya Valiliği Çevre ve Şehircilik İl Müdürlüğü.

LI J. L., HE, M., HAN, W., GU, Y., 2009. Analysis and assessment on heavy metal sources in the coastal soils developed from alluvial deposits using multivariate statistical methods. J Hazard Mater. 164: 976-981.

LJUNG, K., 2006. Metals in urban playground soils, distribution and bioaccessibility. Doctoral thesis Swedish University of Agricultural Sciences, Uppsala. 
Altıntaş (Kütahya-Türkiye) Ovası Tarım Topraklarında Ağır Metal Kirliliğinin Araştırılması, Öncel Çalışma Preliminary Investigation of Heavy Metal Pollution İ Agricultural Soils of Altıntaş (Kütahya-Turkey)

LOSKA, K., WIECHULA, D., BARSKA, B., CEBULA, E., CHOJNECKA, A., 2003. Assessment of arsenic enrichment of cultivated soils in Southern Poland. Polish Journal of Environmental Studies, 12(2), 187-192.

MACHENDER, G., DHAKATE, R., PRASANNA, L., GOVIL, P. K., 2011. Assessment of heavy metal contamination in soils around Balanagar industrial area, Hyderabad, India. Environ Earth Sci, 63, 945-953.Manahan, S.E., 2003. Toxicological Chemistry and Biochemistry. CRC Press, Limited Liability Company (LLC), 3rd edition.

MIKO, S., PEH, Z., BUKOVEC, D., PROHIC, E., KASTMÜLLER, Z., 2000. Geochemical baseline mapping and $\mathrm{Pb}$ pollution assessment of soils in the karst in Western Croatia. Natura Croatica, 9 (1), 41-59.

M. T. A., 2002. 1/500.000 ölçekli Jeoloji Haritası Ankara Paftası, Editör: Turhan N., M.T.A. Yayını, Ankara.

MÜLLER, G., 1969. Index of geo-accumulation in sediments of the Rhine River. Geo J, 2, $108-118$.

MÜLLER, G., 1981. Die Schwermetallbelastung der Sedimenten des Neckars und Seiner Nebenflüsse, Chemiker-Zeitung, 6, 157.

NICHOLSON, F. A., SMITH, S. R., ALLOWAY, B. J., CARLTON- SMITH, C., CHAMBERS, B. J. 2003. An inventory of heavy metals inputs to agricultural soils in England and Wales. Science of the Total Environment. 311: 205-219.

NIEĆ J., BARANOWSKA R., DZIUBANEK G., ROGALA D., 2013. Children's exposure to heavy metals in the soils of playgrounds, sport fileds, sandpits and kindergarten grounds in the region of Upper Silesia. Journal Ecology and Health 17, 2: 55-62.

ÖZBOLAT, G. ve TULİ, A., 2016. Ağır Metal Toksisitesinin İnsan Sağlığına Etkileri. Arşiv Kaynak Tarama Dergisi, 25, 4: 502-521.

PACYNA, J. M., WINCHESTER, J. W., 1990. Contamination of the global environment as observed in the Arctic. Palaeogeogr Palaeoclimatol Palaeoecol, 82, 149-57.

QUEVAUVILlER, P. and LAVIGNE, R., CORTEZ, L., 1989. Impact of industrial and mine drainage wastes on the heavy metal distribution in the drainage basin and estuary of the Sado River (Portugal). Environ Pollut, 59, 267-86.

REIMANN, C. and de CARITAT, P., 2000. Intrinsic flaws of element enrichment factors (EFs) in environmental geochemistry. Environ Sci Technol, 34, 5084-91.

ROMIC, M. and ROMIC, D., 2003. Heavy metals distribution in agricultural topsoils in urban area. Environ. Geol. 43 (7), 795-805.

ROSE, A. W., HAWKES, H. E., WEBB, J. S., 1991. Geochemistry in mineral exploration. London: Academic Press.

SCHIFF, K. C. and WEISBERG, S.B., 1999. IRon as a reference element for determining trace metal enrichment in Southern California coastal shelf sediments. Marine Environmental Research, 48(2), 161-176.

SENGUPTA, S., CHATTERJEE, T., GHOSH, P. B., SAHA, T., 2010. Heavy metal accumulation in agricultural soils around a coal fired thermal power plant (Farakka) in India. Environ Sci Eng, 52(4), 299-306. 
Uygulamalı Yerbilimleri Dergisi, Cilt: 17, No: 1, 2018 (13-26)

Journal of Applied Earthsciences, Vol: 17, No: 1, 2018 (13-26)

Cafer ÖZKUL, vd.

SUTHERLAND, R. A., 2000. Bed sediment-associated trace metals in an urban stream, Oahu, Hawaii. Environ Geol, 39, 611-27.

TOMLINSON, D. L., WILSON, J. G., HARRIS, C. R., JEFFREY, D. W., 1980. Problems in the assessment of heavy- metal levels in estuaries and the formation of a pollution index. Helgolander Meeresunters 33: 566.

THOMSON, I., 1986. Exploration geochemistry: design and interpretation of soil surveys, Rev Econ Geol, 3, 1-18.

VURAL, A., 2014. Toprak ve Akasya Ağacı Sürgünlerindeki İz/Ağır Metal Dağılımı, GümüşhaneTürkiye. Maden Tetkik ve Arama Dergisi, 148: 85-106.

ZHANG, C., 2006. Using multivariate analyses and GIS to identify pollutants and their spatial patterns in urban soils in Galway, Ireland. Environmental Pollution. 142: 501-511.

ZHAO, Y., XU, X., SUN, W., HUANG, B., DARILEK, J. L., SHI, X., 2008. Uncertainty assessment of mapping mercury contaminated soils of a rapidly industrializing city in the Yangtze River Delta of China using sequential indicator cosimulation. Environ. Monit. Assess. 138 (1-3), 343-355.

ZHENG Y., CHEN T., CHEN H., WU H., ZHOU J., LUO, J., HUANG, Z., 2003. The spatial structure and distribution of $\mathrm{Ni}$ contents in soils of suburbs of Beijing. Acta Geographica Sinica, 58(3): 470-476. (in Chinese).

ZHENG Y., YU K., WU H., HUANG, Z., CHEN, H., WU, X., TIAN, Q., FAN, K., CHEN, T., 2002. Lead concentrations of soils in Beijing urban parks and their pollution assessment. Geographical Research, 21(4): 418-424. (in Chinese). 